\title{
Erratum to: Batch and fed-batch growth of Pichia pastoris under increased air pressure
}

\author{
Marlene Lopes · Isabel Belo • Manuel Mota
}

Published online: 21 April 2013

(c) Springer-Verlag Berlin Heidelberg 2013

Erratum to: Bioprocess Biosyst Eng

DOI 10.1007/s00449-012-0871-5

Unfortunately, Eq. 5 has been published incorrectly in the original publication of the article. The corrected version of Eq. 5 is given below:

$k_{\mathrm{L}} a=372 \times P^{-0.38} \times v^{0.33}$

The online version of the original article can be found under doi:10.1007/s00449-012-0871-5.

M. Lopes $\cdot$ I. Belo $(\varangle) \cdot$ M. Mota Centre of Biological Engineering, Institute for Biotechnology and Bioengineering (IBB), University of Minho,

Campus de Gualtar, 4710-057 Braga, Portugal

e-mail: ibelo@deb.uminho.pt 